\title{
FOLLOW UP NUMA COOPERATIVA INTERMEDIADORA DE COMPRAS
}

FOLLOW UP IN AN INTERMEDIATE SHOPPING COOPERATIVE

Recebido em 02.04.2020 Aprovado em 21.04.2020

Avaliado pelo sistema double blind review

DOI: https://doi.org/10.32888/cge.v8i1.41284

\begin{abstract}
Allisson Silva dos Santos
allissonst@hotmail.com

Programa de Pós Graduação em Administração/Universidade Federal da Paraíba - João Pessoa/PB, Brasil https://orcid.org/0000-0001-5121-9553
\end{abstract}

Ana Lúcia Ladislau de Azevedo

analadislau1@gmail.com

Instituto Federal da Paraíba - João Pessoa/PB, Brasil

https://orcid.org/0000-0001-9020-9964

Thiago Gomes Gama

thiagogomesgama@hotmail.com

Instituto Federal da Paraíba - João Pessoa/PB, Brasil

https://orcid.org/0000-0002-3821-5053

Reginaldo Elias Chaves

reginaldoechaves@gmail.com

Instituto Federal da Paraíba - João Pessoa/PB, Brasil

https://orcid.org/0000-0001-5486-6801

Maria da Conceição Monteiro Cavalcanti

mcmcavalcanti2012@gmail.com

Instituto Federal da Paraíba - João Pessoa/PB, Brasil

https://orcid.org/0000-0003-1470-7042

\section{Resumo}

Esta pesquisa teve como objetivo geral identificar de que maneira o follow up pode ser aplicado como garantia do que foi comprado e recebido numa Cooperativa da Construção Civil situada no estado da Paraíba. Classificada como abordagem quanti-qualitativa, obteve-se uma amostra de 23 cooperados que responderam um questionário e um colaborador participou de uma entrevista. A respeito dos resultados, apresentam que, pelo tipo de convivência utilizada com os fornecedores, há alcance dos objetivos, confiança mútua e ganhos rentáveis entre as partes. Portanto, esses pontos colaboram para que exista uma política de follow up efetiva e consistente.

Palavras-chave: Aquisição de Materiais. Fornecedores. Follow up.

\begin{abstract}
This research aimed to identify how the follow up can be applied as a guarantee of what was purchased and received at a Civil Construction Cooperative located in the state of Paraíba. Classified as a quanti-qualitative approach, a sample of 23 members was obtained who answered a questionnaire and one employee participated in an interview. Regarding the results, they show that, due to the type of interaction used with suppliers, objectives are achieved, mutual trust and profitable gains between the parties. Therefore, these points contribute to an effective and consistent follow-up policy.
\end{abstract}

Keywords: Acquisition of Materials. Suppliers. Follow up. 


\section{Introdução}

Diante da realidade de novos entrantes no mercado, as pequenas e médias empresas locais juntam-se como forma de se contrapor à investidura destes. Assim, buscam conhecimento, tecnologia, disposição e abnegação, para, então, trabalhar de forma cooperada ou associativa, pois entenderam que só juntas é que poderiam enfrentar as dificuldades que se desenharam ao longo dos últimos anos, seja na aquisição de bens e serviços de consumo, seja na produção, nas vendas e distribuição, e, mais especificamente, na intermediação da aquisição de insumos.

Numa visão regionalizada no estado da Paraíba, tem-se a presença de uma cooperativa do ramo da construção civil, criada por construtores locais a fim de otimizar, robustecer e, sobretudo, enfrentar a balança desigual na gestão dos seus custos, na aquisição dos insumos inerentes à "cesta" que compõem os itens da construção, cujos potenciais financeiros e econômicos tornam a relação com a concorrência desfavorável. Desse modo, uma melhor forma de comprar seus insumos é fazendo com que seus volumes tomem "corpo", isto é, deixem de ser adquiridos como varejo e passem a ser atacado, e foi com esta visão que a cooperação se tornou realidade.

Porém, nem sempre todo o material comprado é utilizado em sua integralidade, devido, principalmente, a possíveis não conformidades operacionais dos fornecedores, tanto na produção propriamente dita como também na entrega dos materiais. Logo, é preciso fazer um rastreamento periódico e organizado de quais fornecedores prestam os melhores serviços e ofertam os melhores materiais, garantindo a sua perfeita e completa utilização.

A cooperativa estudada atua como sujeito no ciclo de compras, mas não finaliza o ciclo no momento em que negocia e fecha com a nota fiscal do serviço. Nesta lacuna, vem a problemática: Como o follow up (acompanhamento da função compras) pode ser utilizado de forma estratégica por parte da cooperativa intermediadora na aquisição de insumos para construção civil?

Como objetivo geral, fixou-se identificar de que maneira o follow up pode ser aplicado como garantia do que foi comprado e recebido. De forma mais específica, têm-se os seguintes objetivos: a) Identificar o relacionamento da cooperativa com os fornecedores; e b) Apresentar as principais ações de follow up na área de compras.

Justifica-se entender a importância do setor de compras mediante o uso do follow up posto que a função compras não se encerra com o pedido fechado, e sim é estendida até a entrega e a guarda no almoxarifado do cooperado e distribuição entre os setores.

\section{Função Compras}

No mundo da gestão empresarial, num momento mais contemporâneo, vê-se que o aprimoramento da função compras passou a ser fundamental para a administração de recursos materiais de uma empresa. Saber comprar de forma a beneficiar a organização é determinante para a permanência das organizações no mercado. Para isso, é necessário manter um banco de dados de fornecedores atualizado, ter poder de negociação e estabelecer um bom relacionamento entre o cliente e o fornecedor.

Dentro dessa percepção, essa função é responsável por estabelecer o fluxo dos materiais na organização, pela segmentação junto ao fornecedor e, também, pela agilidade da entrega. O ciclo de compra ideal consiste nos seguintes passos: a) Receber e analisar requisições de compra; b) Identificar e selecionar fornecedores; c) Solicitar cotações; d) Determinar o preço certo; e) Emitir ordem de compra; f) Entregar o suprimento; g) Receber e aceitar mercadorias e h) Aprovar fatura do fornecedor (ARNOLD, 1999).

Ademais, as atividades de compras têm como objetivo obter e coordenar o fluxo contínuo de suprimentos de modo a atender às necessidades de produção; comprar os materiais com melhores preços sem fugir dos parâmetros qualitativos e quantitativos; e procurar as melhores condições para a organização (DIAS, 2005). O setor de compras também tem uma inter-relação com os níveis de estoque, sendo de competência do mesmo equilibrar a quantidade de materiais a serem comprados, para que os outros departamentos encontrem-se satisfeitos continuamente (DIAS, 2005). Logo, a área de compras tem uma função importante em ter o cuidado para que os níveis de estoque da empresa estejam sempre em equilibrio. 


\section{Allisson Silva dos Santos, Ana Lúcia Ladislau de Azevedo, Thiago Gomes Gama, Reginaldo Elias Chaves e Maria da Conceição Monteiro Cavalcanti}

No entanto, garantir fontes que sejam confiáveis para o fornecimento de materiais é um dos problemas existentes na atividade de compras. Por isso, conhecer os fornecedores é condição essencial para o seu bom desenvolvimento. Um excelente fornecedor entregará a quantidade pedida no tempo prometido, no preço combinado e com qualidade satisfatória. No que se refere às operações de compras, elas podem ser sistematizadas, por meio de passos bem definidos, conforme as perguntas: para quem?; o que?; de quem?; quando?; quanto?; que preço devo comprar? (TRIGUEIRO, 2007).

Contudo, é importante que o setor de compras e o planejamento e controle da produção tenham uma boa relação, pois, quando ambos trabalham juntos, a responsabilidade pelo material é ampliada, desde o momento da aquisição até a entrega. Em razão disso, o controle deve ser rigoroso, de modo a garantir qualidade e ter a confirmação que o pedido esteja de acordo com o que foi solicitado (DIAS, 2010).

Outrossim, quando há uma solicitação de algum tipo de suprimento, a função de compras deve primeiramente identificar os potenciais fornecedores, após a identificação, fazer um pedido de compras e, posteriormente, coordenar a operação dos detalhes técnicos e entrega do produto ou serviço solicitado (SLACK; CHAMBERS; JOHNSTON, 2009).

\section{Relacionamento com Fornecedores}

Com o mercado cada vez mais acirrado no sentido de competitividade, as organizações precisam estar com uma comunicação efetiva e eficiente com os envolvidos no processo de desenvolvimento dos produtos e/ou dos serviços. Neste sentido, um dos envolvidos mais importantes para a concretização dos objetivos é o fornecedor, pois ele que dá início ao processo através de insumos, e com ele deve ser estabelecido um relacionamento salutar. Durante os estudos relacionados à área, foram segmentados os vínculos que as empresas possuem com os seus fornecedores, que, de acordo com as obras de Dyer (1997) e Dyer, Cho e Chu (1998) (apud BRONZO, 2004), as organizações podem segmentar seus vínculos em três tipos de regimes, sendo eles chamados de arm's length, de quase-mercado e de parceria.

Isso posto, o primeiro regime, arm's length, configura-se pela tentativa dos contratantes de minimizar sua dependência em relação aos fornecedores ao máximo, aumentando as possibilidades de negociar preços ou outras condições do fornecimento com uma volumosa quantidade de fornecedores (BRONZO, 2004). Com isso, a frequência de envolvimento, de trocas de mensagens entre o fornecedor e a organização será menor, em razão do baixo valor agregado às compras efetuadas. No segundo, regime de quase-mercado, os materiais de aquisição são considerados como não estratégicos, embora representem entradas de valia à produção da contratante, podem não ser considerados estratégicos por não abrangerem ativos específicos; por possuírem menor valor agregado; por não estarem diretamente nos processos produtivos e nas competências centrais da organização compradora; ou por serem materiais de uso indireto (BRONZO, 2004).

Por último, o regime de parceria apresenta outros ideais e motivações, fundamentalmente diferentes das características e motivações presentes nos regimes anteriores. Nesta segmentação de fornecedores em regime de parceria, há aparentemente uma identidade característica do período Japão pós-guerra, tendo sido impulsionado um modelo de gestão particular para o relacionamento entre empresas e a gestão das cadeias de suprimento, que, em grande maioria, foi sustentado por práticas colaborativas no tocante à integração de processos produtivos e logísticos entre as empresas (BRONZO, 2004). De fato, este regime proporciona um sentido de cooperação entre o fornecedor e o comprador, em que há trocas de informações constantes e a preocupação para que as partes saiam ganhando nas negociações, transformando-se numa relação saudável.

Vale ressaltar, ainda, a importância do tipo de vínculo estabelecido entre as partes, pois o alcance dos objetivos organizacionais recebe influência do tipo de relacionamento que é adotado para o tratamento das negociações comerciais (FURTADO, 2005). Nesse contexto, em situações de parceria, o fornecedor se torna um auxiliador no desenvolvimento do produto, na análise e melhorias do processo produtivo de seu cliente, se compromete com a qualidade, e, em troca disso, ganha um contrato periódico, dependendo das necessidades existentes, garantindo uma relação de ganha-ganha entre as partes, evidenciando a presença de uma integração estratégica, que é atingido o comakership (MARTINS; ALT, 2009). 
Assim sendo, um dos mecanismos mais valiosos para o relacionamento do comprador com o fornecedor é a confiança mútua, onde quanto mais aberta e clara a negociação, maiores são as chances de boa compra (DIAS, 2009). O relacionamento entre comprador e fornecedor gera não só vínculos comerciais, como também maiores proximidades para o desenvolvimento de soluções de problemas, assessoramento técnico, negociações e esclarecimento de dúvidas (MONTE ALTO; PINHEIRO; ALVES, 2009).

Todavia, a capacidade da geração de valor dentre resultados almejados com a atividade de compras pode ser alcançado com fundamentos baseados na ética. Conforme Monte Alto, Pinheiro e Alves (2009), a contrapartida da excelência relacionada ao resultado alcançado na compra de materiais e serviços para as organizações, que provocam reduções de custos, positividades refletidas na produção, no operacional e nas demais áreas chaves de uma organização, é a fundamentação dos processos científicos, tendo como pilar de sustentação e base de ação a ética pessoal e profissional.

\section{Sistema de Follow up em Compras}

Os insumos utilizados em qualquer segmento de produção como construção civil, automobilístico, dentre outros, têm como origem elementos naturais, ou seja, provenientes do meio ambiente. Por esse motivo, e, especialmente, em tempos de dificuldades econômicas, faz-se mais que necessário um acompanhamento minucioso da utilização dessas matérias para se reduzir desperdícios e prejuízos. Para isso, existe um conceito comumente difundido na gestão de compras, denominado de follow up, que é a supervisão do processo de aquisição de materiais, com vistas ao perfeito e completo recebimento e utilização do material comprado.

Dessarte, esse sistema vem justamente para enfatizar a responsabilidade do comprador, lembrando que (quando eficaz) deve gerar e atualizar periodicamente um arquivo com o registro de diversas informações acerca dos materiais, como, por exemplo: vida útil do produto; variações de preços; modificações das quantidades pedidas; indicação de nova condição de pagamento e entradas de mercadorias correspondentes às solicitações. Consequentemente, falhar nesses registros ou apresentar insuficiência de dados podem acarretar uma má performance das atividades de compras (DIAS, 1983).

Como qualquer outro sistema gerencial, o follow up tem objetivos, metas a alcançar, que, no caso, abrange não só verificar a metodologia de compras, mas também auxiliar nos processos produtivos e consequentes resultados organizacionais dos adquirentes dos insumos. Em outras palavras, a meta deste controle do processo é assegurar que o resultado da produção seja o desejado, estratificar alterações, determinar ações corretivas, e, ainda, verificar limitações existentes, conforme dito por Lubben (apud GONZALES, 2003). Nessa lógica, quem fornece os materiais comprados é objeto fundamental neste acompanhamento, portanto, recomenda-se a criação de um programa de avaliação de fornecedores, através de um sistema de méritos e deméritos, observada a qualidade de suas entregas. Deve-se, posteriormente, registrar as informações deste sistema em fichas de fornecedor ou banco de dados, visando à possibilidade de alteração de status do fornecedor, segundo argumenta Oliveira (apud GONZALES, 2003).

Logisticamente falando, a efetiva entrega de mercadorias deve ser compreendida desde o acompanhamento de sua compra até a legítima recepção delas. Para isso, a prossecução do sistema de aquisição deve estar sincronizada com a de recebimento. Logo, tanto a responsabilidade de entrega da mercadoria pelo fornecedor quanto a recepção dela pelo comprador são trabalhadas no sistema de logística e de acompanhamento em compras (GONZALES, 2003). Esse sistema vem precisamente para enfatizar a responsabilidade do comprador, lembrando que este (quando eficaz) deve gerar e atualizar periodicamente um arquivo com o registro de diversas informações acerca dos materiais, como, por exemplo: vida útil do produto; variações de preços; modificações das quantidades pedidas; indicação de nova condição de pagamento e entradas de mercadorias correspondentes às solicitações. Consequentemente, falhar nesses registros ou apresentar insuficiência de dados podem acarretar uma má performance das atividades de compras (DIAS, 2010).

No que tange à condução desse sistema, o follow up pode ser do tipo preventivo ou corretivo, realizado no ambiente interno ou externo. O follow up preventivo visa evitar atrasos na entrega de materiais encomendados junto aos fornecedores, mediante o monitoramento daquilo que ainda vai vencer. Já o corretivo, esse é definido como aquilo que evita que atrasos já existentes sejam mais longos do que deveriam, para não aumentarem os problemas, tendo em vista que o planejamento sofrerá perda ou custo (MARTINS; SANTOS, 2017). 
Sobre o follow up interno, consiste em acompanhar os processos internos ou áreas da organização que processam o pedido. São consideradas também as atividades produtivas necessárias para a finalização do produto, ou seja, a produção propriamente dita (MARTINS; SANTOS, 2017). Na ótica externa, este acompanhamento busca a manutenção do fluxo contínuo de insumos no setor produtivo, evitando atrasos ou faltas, acompanhando o monitoramento de entregas, que vai desde o contato com o fornecedor no envio e aceite do pedido de compra aprovado até o recebimento do material (aprovado) de forma direta com os fornecedores (MARTINS; SANTOS, 2017).

Acerca do follow up externo, quando realizado de forma direta ao fornecedor, é denominado de pessoal, pois não utiliza ferramentas do sistema ERP ou módulos eletrônicos especificamente para monitoramento. Monitora-se mediante ligações telefônicas, e-mails diretos ao fornecedor ou visitas. No acompanhamento externo de forma eletrônica, pode-se utilizar softwares que compõem o sistema ERP, assim como é possível criar um portal eletrônico com acesso pelos fornecedores ou através de e-mails automáticos com informações de seus itens em carteira (MARTINS; SANTOS, 2017).

Portanto, para o sucesso de todo o processo de aquisição de materiais, é necessária tanto a ciência das atribuições e responsabilidades dos compradores e fornecedores quanto o fiel cumprimento delas por parte dos mesmos envolvidos.

\section{Procedimentos metodológicos}

Este estudo, que teve como objetivo identificar de que maneira o follow up pode ser aplicado para garantir o recebimento de produtos com as características desejadas, possuiu natureza de pesquisa aplicada, existindo o interesse na aplicação e utilização dos conhecimentos em realidades circunstanciais (GIL, 2008). Ele se denominou como pesquisa quanti-qualitativa, por sua análise ser elaborada considerando a interpretação dos resultados obtidos por dados alfabéticos e numéricos (SILVA; MENEZES, 2001). Quanto aos objetivos, este trabalho foi caracterizado como pesquisa descritiva, por estar focada em coletar informações sobre opiniões e atitudes de determinado conjunto de pessoas, relacionadas a específicas temáticas (GIL, 2008).

Além disto, em relação aos procedimentos técnicos, esta pesquisa foi considerada como bibliográfica, por seu embasamento ter sido construído por via de livros e artigos já publicados. De acordo com Marconi e Lakatos (2010), esse tipo de pesquisa abrange ampla bibliografia de temas de estudo que tenha se tornado pública, permitindo para os leitores o conhecimento sobre o que já foi estudado. Também, ela foi considerada como pesquisa de campo, que, segundo os mesmos autores, consiste na observação de fatos que acontecem no momento do levantamento de dados e nos registros das variáveis que são relevantes para a área de gestão de recursos materiais e documental, por explorar documentos da empresa que ainda não receberam tratamento científico (GIL, 2008).

O universo definido para colher os dados foi composto por 40 cooperados que recebem os insumos dos fornecedores, pela intermediação da cooperativa, e o quadro laboral desta cooperativa intermediadora. Para coletar os dados, foi elaborado um questionário com 24 questões fechadas, sendo ele respondido por uma amostra de 23 cooperados, e uma entrevista estruturada respondida por um colaborador da empresa intermediadora na compra dos insumos, sendo tal colaborador selecionado por conveniência. Conforme Gil (2008), a entrevista estruturada se desenvolve a partir de perguntas fixas, em que a ordem e leitura delas permanecem constantes para $o$ respondente.

Os dados encontrados por intermédio dos instrumentos de coleta de dados foram analisados por medidas estatísticas simples, envolvendo frequência e percentual, utilizando o software Excel, como também de forma qualitativa, por meio do insumo teórico demonstrado nesta pesquisa. 


\section{Apresentação e análise dos resultados}

\section{Identificando o relacionamento da cooperativa com os fornecedores}

Para definir o tipo de relacionamento adotado com os fornecedores pela cooperativa, foram respondidas, por um representante da cooperativa, 10 perguntas presentes no roteiro de entrevista, em que foram evidenciadas a influência, a troca de ideias e de soluções entre as partes, as características deste tipo de relação, entre outros fatores.

Considerando a colocação de Furtado (2005), de que o relacionamento com os fornecedores é importante por influenciar no alcance dos objetivos organizacionais, o entrevistado relatou que concorda com essa afirmação, já que a cooperativa atinge seu objetivo de atender a necessidade do cooperado através de um relacionamento sério, com uma comunicação clara, transparente e ética, e que isso resulta na oferta de produtos e/ou serviços num custo menor e com a qualidade que o cooperado precisa.

Em relação à confiança mútua sentida entre os fornecedores e a cooperativa, o respondente disse que a cooperativa tenta gerar um ambiente em que o fornecedor se sinta confortável, confiante, para ele distribuir informações que, normalmente, ele não colocaria numa negociação fria, como também faz com que exista a perspectiva de reciprocidade, e isso tem gerado negociações boas e visíveis através do processo chamado pelo respondente de ciclo virtuoso, em que o cooperado compra porque avalia, faz suas análises, entende que o negócio está competitivo, que está dentro do objetivo esperado e autoriza a continuação da negociação pela cooperativa, se transformando num processo rotineiro para os envolvidos por ser benéfico. Corroborando com isso, Dias (2009) cita que um dos tópicos mais importantes para este relacionamento é a confiança mútua, quanto mais aberta e clara a negociação, maiores são as chances de boa compra, sendo confirmado isso com a observação da fala do entrevistado.

Além disso, o respondente foi questionado sobre os ganhos gerados por este tipo de convívio, em que o mesmo relatou que tem gerado otimização de produção e de custos e tem gerado relacionamento sério, pois não há como uma cooperativa, que se relaciona com vários fornecedores, dar assistência a vários cooperados para acontecer o negócio, se não for com ética e com transparência. Esse ponto de vista entra em consonância com a fala de Dias (2009) de que devem ser almejadas a otimização da produção e dos custos, o relacionamento sério, contratos corretos, pesquisa de novas alternativas e a discussão desses tópicos com os envolvidos.

A respeito dos 3 tipos de regimes de relacionamento apresentados na fundamentação teórica, o gestor considerou que todos eles existem dentro do campo de fornecedores, sendo o mais frequente o regime de parceria. Para o regime de parceria, constatou-se sua existência através dos fornecedores que oferecem palestras técnicas, análises da obra, soluções e compromisso com as atividades das cooperativas e dos cooperados, e, pelo lado da cooperativa, a mesma costuma dizer que a cooperativa é a segunda casa do fornecedor, que está sempre pronta para acolher e trocar ideias sobre os produtos e serviços, demonstrando a utilização de práticas colaborativas.

No que se refere à perspectiva ganha-ganha desse regime, o respondente salientou que, baseando-se nisto, é possível perceber que os três atores (fornecedores, cooperativa e cooperados) saem ganhando nas negociações, que, de acordo com Martins e Alt (2009), essa relação garante um cotidiano de ganha-ganha entre as partes, evidenciando a presença de uma integração estratégica entre os envolvidos, como também o fornecedor se torna para a empresa um auxiliador no desenvolvimento dos produtos, nas análises, nas melhorias e na qualidade do processo produtivo.

No que diz respeito ao regime arm's length, que, conforme Bronzo (2004), configura-se pelo contratante tentar minimizar sua dependência em relação aos fornecedores ao máximo, aumentando as possibilidades de negociar preços ou outras condições do fornecimento com uma elevada porção de fornecedores, o entrevistado relatou que acontece isso com alguns insumos que os cooperados precisam, com, por exemplo, o elevador, e com outros insumos não, tendo categorias que são mais viáveis negociar com vários e categorias que é interessante repassar o volume para alguns fornecedores.

$\mathrm{Na}$ abordagem do regime de quase-mercado, o respondente explanou que existem fornecedores com esse tipo de relacionamento, mas que não é prioridade dentro da cooperativa, acontecendo ocasiões em que esse tipo de relacionamento não é de qualidade, e que acaba gerando muita explicação, muito esforço e uso de muito tempo da cooperativa, mediante às outras coisas em maior volume que são mais rentáveis. Segundo Bronzo (2004), tal regime se baseia em negociação de materiais que podem ser considerados não estratégicos por não abrangerem ativos 
específicos, por ter baixo valor agregado, por serem materiais de uso indireto ou por não estarem diretamente nos processos produtivos e nas competências centrais da empresa adquirente.

Considerando o assessoramento que pode ser feito através dos fornecedores, o respondente relatou que existem fornecedores que disponibilizam uma equipe para fiscalizar, treinar, orientar e desenvolver os colaboradores dos cooperados, e que ainda existem os fornecedores que apenas pensam em fabricar, vender e entregar, sem se preocupar com a pós-venda. Isso entra em conformidade parcialmente com o que Monte Alto, Pinheiro e Alves (2009) dizem, de que o relacionamento entre comprador e fornecedor não gera apenas relações comerciais, pois gera, também, relações para o desenvolvimento de soluções dos problemas, assessoramento técnico, negociações e esclarecimento de dúvidas. Nesse caso, a parcialidade acontece porque nem todos fornecedores se sujeitam a agir da forma como os autores citam, e alguns agem somente como um tratado de vínculo comercial.

\section{Apresentando as principais ações de follow up na área de compras}

O questionário respondido por 23 cooperados da cooperativa teve sua elaboração e análise baseadas na teoria dos autores fundamentados na pesquisa. Para a interpretação dos dados coletados, consideraram-se os percentuais das respostas mais relevantes às variáveis tratadas em cada assertiva. A Tabela 1 contém as afirmativas e os devidos percentis gerados através das respostas dos questionados.

Considerando o cumprimento dos prazos, obteve-se o percentil de $100 \%$, denotando que os prazos são cumpridos com uma ótima frequência. Destarte, os respondentes subsidiam a cooperativa para que ela valorize ainda mais a implementação do follow up em seus processos, pois esse sistema permitirá à cooperativa tomar decisões que culminam na entrega das mercadorias nos prazos corretos, minimizando perdas (GONZALES, 2003).

Entretanto, mais do que chegar no prazo estipulado, é necessário que a entrega seja efetuada em horários que garantam a sua execução integral, sem causar inconvenientes para nenhuma das partes envolvidas (fornecedor e cooperado). A partir das respostas, percebe-se que, na grande maioria das entregas, com 95,65\%, isso é cumprido.

A qualidade é outro ponto abordado pelo follow up, visto ser uma variável indispensável na gestão de processos de compra. Então, por ter sido obtido 100\% de concordância quanto à suficiência dela nos materiais adquiridos pela cooperativa, e prezando pela continuidade do sucesso da mesma, a cooperativa deve considerar a adoção do acompanhamento em compras (MARTINS; SANTOS, 2017).

Em relação à parada da produção por falta de material devido a problemas que tenham surgido com fornecedor, 95,65\% dos cooperados afirmaram que isso raramente ou nunca acontece, corroborando para a hipótese de sinergia entre as partes em relação às entregas solicitadas, considerando também que os cooperados não programam gastar mais devido à falha no processo de compras, que não é executado por eles.

Do ponto de vista financeiro, a maioria dos cooperados, com $56,52 \%$, tem prejuízo quando a entrega do material atrasa. O follow up aperfeiçoa a relação entre o comprador e o fornecedor, para que isso viabilize o sucesso e a consecução do processo de compras por parte da cooperativa.

Sobre a importância deste acompanhamento, $82,61 \%$ dos respondentes concordam de sua necessidade, visto ser necessário para a redução dos empecilhos supracitados (paradas, custos adicionais). Portanto, é válido relembrar que tanto a responsabilidade de entrega da mercadoria pelo fornecedor quanto a recepção dessa pelo comprador são trabalhadas no sistema de acompanhamento em compras (GONZALES, 2003). 
Tabela 1: Afirmativas sobre follow up

\begin{tabular}{|c|c|c|c|}
\hline Afirmativa & $\begin{array}{c}\text { Sempre } \\
\text { ou } \\
\text { Frequentemente }\end{array}$ & Às vezes & $\begin{array}{l}\text { Raramente } \\
\text { ou } \\
\text { Nunca }\end{array}$ \\
\hline $\begin{array}{l}\text { Os materiais comprados através da cooperativa são entregues pelos } \\
\text { fornecedores nos prazos estipulados. }\end{array}$ & $100 \%$ & $0 \%$ & $0 \%$ \\
\hline $\begin{array}{c}\text { As entregas são efetuadas em horários convenientes para o pessoal } \\
\text { responsável pela recepção das mesmas. }\end{array}$ & $95,65 \%$ & $4,35 \%$ & $0 \%$ \\
\hline $\begin{array}{l}\text { Os materiais apresentam qualidade suficiente para garantir uma boa } \\
\text { produção. }\end{array}$ & $100 \%$ & $0 \%$ & $0 \%$ \\
\hline $\begin{array}{l}\text { Já tive minha produção parada por falta de material, devido à falha } \\
\text { (qualquer que seja) do fornecedor. }\end{array}$ & $0 \%$ & $4,35 \%$ & $95,65 \%$ \\
\hline Esta parada me traz custos adicionais (não programados). & $13,04 \%$ & $34,78 \%$ & $52,17 \%$ \\
\hline $\begin{array}{l}\text { Estes custos são, na maior parte, com o aumento de preço dos materiais que } \\
\text { precisam ser comprados imediatamente para não prolongar esta parada. }\end{array}$ & $30,43 \%$ & $21,74 \%$ & $47,83 \%$ \\
\hline $\begin{array}{l}\text { Estes mesmos custos da última questão também são observados quando } \\
\text { conseguimos comprar a tempo de evitar a parada de produção. }\end{array}$ & $56,52 \%$ & $30,43 \%$ & $13,04 \%$ \\
\hline $\begin{array}{l}\text { Um acompanhamento direto e contínuo por parte da cooperativa referente } \\
\text { às entregas (prazos e qualidade dos materiais) dos fornecedores poderia } \\
\text { reduzir estes acontecimentos (parada de produção e custos adicionais). }\end{array}$ & $82,61 \%$ & $17,39 \%$ & $0 \%$ \\
\hline Este acompanhamento traria mais credibilidade à cooperativa. & $95,65 \%$ & $4,35 \%$ & $0 \%$ \\
\hline $\begin{array}{l}\text { Esta maior credibilidade poderia aumentar a frequência das minhas } \\
\text { solicitações de compra junto à cooperativa. }\end{array}$ & $95,65 \%$ & $4,35 \%$ & $0 \%$ \\
\hline $\begin{array}{c}\text { Esta maior credibilidade poderia aumentar a quantidade solicitada em kg, } \\
\text { metro etc., em meus pedidos de compra junto à cooperativa. }\end{array}$ & $91,30 \%$ & $8,70 \%$ & $0 \%$ \\
\hline $\begin{array}{l}\text { Considero importante a cooperativa receber feedback (informações) sobre } \\
\text { como se deu a recepção dos materiais adquiridos por intermédio dela, para, } \\
\text { então, prestar um melhor serviço ao seu cooperado. }\end{array}$ & $86,96 \%$ & $13,04 \%$ & $0 \%$ \\
\hline Disponibilizarei cópia física ou virtual dos documentos das entregas. & $52,17 \%$ & $26,09 \%$ & $21,74 \%$ \\
\hline $\begin{array}{c}\text { Considero fundamental a cooperativa registrar e atualizar a qualidade das } \\
\text { entregas realizadas pelos fornecedores. }\end{array}$ & $78,26 \%$ & $21,74 \%$ & $0 \%$ \\
\hline $\begin{array}{l}\text { Vejo como necessário a cooperativa estar sempre atenta a possíveis } \\
\text { alterações produtivas e limitações minhas, visando (ela) à adoção de ações } \\
\text { corretivas para uma melhor prestação de serviço. }\end{array}$ & $73,91 \%$ & $21,74 \%$ & $4,35 \%$ \\
\hline Esta atenção também deve ser observada nos processos dos fornecedores. & $86,96 \%$ & $8,70 \%$ & $4,35 \%$ \\
\hline $\begin{array}{l}\text { É indispensável a cooperativa acompanhar, junto ao fornecedor, o processo } \\
\text { de entrega dos materiais para evitar atrasos nele. }\end{array}$ & $82,61 \%$ & $17,39 \%$ & $0 \%$ \\
\hline $\begin{array}{c}\text { Em caso de atrasos, tal acompanhamento continua sendo necessário para } \\
\text { evitar maiores prejuízos à minha produção. }\end{array}$ & $78,26 \%$ & $21,74 \%$ & $0 \%$ \\
\hline $\begin{array}{l}\text { A cooperativa precisa acompanhar seus processos internos (relacionados às } \\
\text { compras) a fim de melhorá-los e garantir um serviço adequado aos } \\
\text { cooperados. }\end{array}$ & $73,91 \%$ & $26,09 \%$ & $0 \%$ \\
\hline $\begin{array}{l}\text { O acompanhamento da cooperativa junto aos fornecedores é essencial para } \\
\text { não prejudicar meu processo produtivo. }\end{array}$ & $91,30 \%$ & $8,70 \%$ & $0 \%$ \\
\hline $\begin{array}{c}\text { A cooperativa deve manter e atualizar um arquivo com diversas informações } \\
\text { acerca dos materiais adquiridos por intermédio dela, como, por exemplo: } \\
\text { vida útil deles; variações de preços; condições de pagamento; entrada de } \\
\text { material conforme as solicitações; etc. }\end{array}$ & $82,61 \%$ & $17,39 \%$ & $0 \%$ \\
\hline $\begin{array}{c}\text { Na minha opinião, implantar estas medidas fará com que a cooperativa } \\
\text { potencialize, aperfeiçoe suas atividades de compras. }\end{array}$ & $95,65 \%$ & $4,35 \%$ & $0 \%$ \\
\hline $\begin{array}{c}\text { Consequentemente, sentirei-me mais seguro para adquirir material por } \\
\text { intermédio da cooperativa. }\end{array}$ & $91,30 \%$ & $8,70 \%$ & $0 \%$ \\
\hline
\end{tabular}

Fonte: Dados da pesquisa (2018). 


\section{Allisson Silva dos Santos, Ana Lúcia Ladislau de Azevedo, Thiago Gomes Gama, Reginaldo Elias Chaves e Maria da Conceição Monteiro Cavalcanti}

Diante do percentual de $95,65 \%$, é possível afirmar que os cooperados também veem como benéfica para a cooperativa a implantação do follow up, pois a faria ter mais credibilidade. Além disso, os 65,22\% positivos para a assertiva posterior mostram como o sistema citado pode expandir o alcance, as parcerias da cooperativa, uma vez que novas adesões e novos contentamentos dos cooperados tendem a se prolongarem cada vez mais, quando mantida a credibilidade da cooperativa.

Tão importante quanto prospectar novos, é garantir que os cooperados já existentes maximizem a ocorrência de pedidos de compras junto à cooperativa. Dessa maneira, implantando o follow up de forma eficaz e eficiente, as empresas cooperadas, com 95,65\%, apontam o quanto isso poderia ser observado nas suas relações com a cooperativa. Analogamente, em $91,30 \%$ das respostas, elas afirmam que uma cooperativa confiável faz com que as quantidades solicitadas nos pedidos de compra também aumentem, até porque tal ação acarreta redução de custos para os cooperados.

As empresas cooperadas, somando $86,96 \%$ de sempre ou frequentemente, nortearam a cooperativa quanto à importância de feedbacks à cooperativa em relação às entregas dos materiais, mostrando a necessidade de uma melhor prestação do serviço. Para um acompanhamento em compras, é preciso obter informações, sejam de forma física ou virtual, nas mais diversas mídias. De forma básica, isso dará subsídios para que as organizações possam estabelecer e manter procedimentos documentados que assegurem que os produtos comprados estejam de acordo com os requisitos especificados (OLIVEIRA apud GONZALES, 2003).

Conforme o percentil de 78,26\% somando sempre e frequentemente, os cooperados expressam o desejo ou talvez até a necessidade deste registro sobre a qualidade das entregas dos fornecedores. Para tanto, deve-se criar um programa de avaliação de fornecedores, mediante um sistema de méritos e deméritos, que seja possível a alteração de status do fornecedor (OLIVEIRA apud GONZALES, 2003).

A ideia de que é preciso e desejável um acompanhamento mais minucioso por parte da cooperativa é reforçada pela concordância de $73,91 \%$, pois o follow up visa não só verificar a metodologia de compras, mas também auxiliar e muito nos processos produtivos e consequentes resultados organizacionais dos adquirentes dos insumos. Assim, conclui-se que uma das metas deste controle do processo é assegurar que o resultado da produção seja o desejado, estratificando alterações, determinando ações corretivas e, ainda, identificando limitações existentes (LUBBEN apud GONZALES, 2003). É apontado, também, com 86,96\%, que esse acompanhamento deve ser observado nos processos dos fornecedores, visto que, obviamente, são partícipes da relação de compra e venda.

A grande maioria, com 82,61\%, concorda que o acompanhamento da cooperativa junto ao fornecedor é indispensável para evitar atrasos na entrega de materiais encomendados. Neste caso, o monitoramento é chamado de preventivo, justamente por ser em relação a aquilo que ainda vai vencer (MARTINS; SANTOS, 2017). Mesmo tal acompanhamento citado venha a falhar, $78,26 \%$ dos cooperados confirmam que é necessário continuar monitorando, de forma corretiva, para que, assim, não se prolongue o atraso na entrega, e se evitem maiores problemas e prejuízos do que os já existentes e percebidos (MARTINS; SANTOS, 2017).

Das empresas cooperadas, $73,91 \%$ dos respondentes ratificam a necessidade de a cooperativa praticar o follow up interno, buscando a melhoria contínua através do acompanhamento dos próprios processos e áreas internas que processam o pedido (MARTINS; SANTOS, 2017). De forma análoga, 91,30\% certificam que é impreterível o acompanhamento externo junto ao fornecedor, evitando atrasos ou faltas, monitorando as entregas, abrangendo desde o contato com o fornecedor no envio e aceite do pedido de compra aprovado até o recebimento do material também aprovado (MARTINS; SANTOS, 2017).

Relembrando a responsabilidade de um comprador eficaz, 82,61\% dos cooperados atestam que a cooperativa deve manter e atualizar, periodicamente, um arquivo com registro da vida útil do produto, variações de preços, indicação de nova condição de pagamento e entradas de mercadorias correspondentes às solicitações, pois, consequentemente, falhar nesses registros ou apresentar insuficiência de dados podem acarretar uma má performance das atividades de compras (DIAS, 2015).

Além disso, 95,65\% dos respondentes afirmam que a implantação do follow up pela cooperativa potencializará e aperfeiçoará as atividades de compras da mesma, permitindo, assim, que ela vislumbre uma maior prospecção de cooperados. Por fim, enfatiza-se ainda que $91,30 \%$ ressaltam o quanto este acompanhamento em compras poderá otimizar não só os processos da cooperativa, mas também a imagem dela perante seus cooperados. 


\section{Considerações finais}

Este estudo atingiu o objetivo de identificar de que maneira o follow up pode ser aplicado como garantia do que foi comprado e recebido numa Cooperativa da Construção Civil situada no estado da Paraíba, em que possui o papel de intermediação da aquisição de insumos, demonstrando que a efetividade do follow up é capaz de potencializar e aperfeiçoar as atividades organizacionais.

Tendo em vista as posições dos respondentes do questionário elaborado e analisado à luz da literatura, torna-se nítida a percepção comprobatória de que o sucesso deste negócio perpassa pela observação, implementação, manutenção e apoio de todos os envolvidos no follow up, considerando ser unânime entre estes que os prazos de entregas estão conforme suas necessidades e a qualidade dos produtos é suficiente para garantir uma boa produção com 100\% de concordância entre os respondentes.

Percebe-se também, o quanto é indispensável uma relação de parceria com os fornecedores, em que no cenário estudado há alcance dos objetivos, confiança mútua e ganhos rentáveis entre as partes (cooperativa e fornecedores), em que é preciso que empresas estabeleçam e cultivem esse tipo de relação, visto que gera vantagens para a efetividade da missão organizacional, e Martins e Alt (2009) enfatiza que essa relação garante um cotidiano de ganha-ganha entre as partes.

As contribuições geradas por esse estudo se encontram no feedback dado à cooperativa intermediadora em relação à opinião de seus clientes sobre características do follow up, na demonstração da importância de um follow up para empresas que nascem com o intuito de fazer a intermediação de compras, para outras que regularmente necessitam de vastos recursos materiais, e para empresas que trabalham com poucos recursos materiais, mas que precisam manter uma gestão eficiente deles. É preciso levar em consideração, também, que a pesquisa oportunizou ampliar o debate da importância do follow up no universo científico, fomentando ainda mais a área de gestão de materiais.

Como sugestões para futuras pesquisas, tem-se verificar as influências do follow up em outros ramos, sem ser da construção civil; a comparação de resultados financeiros entre empresas que oficialmente adotam o sistema follow up e empresas que não adotam e verificar a opinião de gestores sobre a adoção do follow up em sua rotina.

Por último, evidencia-se por todos os respondentes da pesquisa que a implantação do follow up não é somente um procedimento puro e simples, mas, de sobremaneira, uma poderosa ferramenta, que, além de otimizar interna e externamente os processos de compras, potencializará a pujança corporativa dos negócios cooperados deste processo, creditando mais valor ao seu trabalho e originando mais credibilidade entre os integrantes da cooperativa. Então, o follow up tem a premissa de tornar mais profissional e eficiente um processo que não só objetiva a compra, isto é, ele acompanha de maneira cíclica o desempenho da operação, no entanto, o seu sucesso está ligado à participação de todos, com suas respectivas atribuições.

\section{Referências}

ARNOLD, J. R. Tony. Administração de Materiais. São Paulo, Editora Atlas S. A., 1999.

BRONZO, Marcelo. Relacionamentos Colaborativos em Redes de Suprimentos. Revista de Administração de Empresas, Minas Gerais, v. 44, n. 4, p.61-73, 2004.

DIAS, M. A. P. Administração de Materiais: uma abordagem logística. São Paulo: Atlas, 1983.

DIAS, M. A. P. Administração de Materiais. São Paulo, Editora Atlas, 2005.

DIAS, Marco Aurélio P. Administração de Materiais: Princípios, Conceitos e Gestão. São Paulo: Atlas S.A., 2009

DIAS, M. A. P. Administração de Materiais: uma abordagem logística. São Paulo:

Atlas, 2010

FURTADO, Gustavo Adolfo Pudenci. Critérios de seleção de fornecedores para relacionamento de parceria: um estudo em empresas de grande porte. 2005. 131 f. Dissertação (Mestrado) - Curso de Administração, Universidade de São Paulo, São Paulo, 2005. 
GIL, Antônio Carlos. Métodos e técnicas de pesquisa social. 6. ed. São Paulo: Atlas, 2008.

GONZALES, M. K. O sistema de acompanhamento em compras e logística numa organização pública. Revista Semina: Ciências Sociais e Humanas. Londrina: UEL v. 24, n. 1, 2003, p. 53-74. Disponível em:

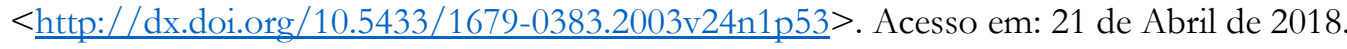

MARCONI, Marina de Andrade; LAKATOS, Eva Maria. Fundamentos da Metodologia Científica. São Paulo: Atlas S.A., 2010.

MARTINS, F. S.; SANTOS, I. J. Follow up em compras: enfrentando desafios e colhendo resultados. Artigo Técnico (Pós-graduação em Administração) - Curso de Administração de compras e suprimentos, Faculdade Ietec de Belo Horizonte, 2017, 9f.

MARTINS, Petrônio Garcia; ALT, Paulo Renato Campos. Administração de Materiais e Recursos Patrimoniais. São Paulo: Saraiva, 2009.

MONTE ALTO, Clésio Feres; PINHEIRO, Antônio Mendes; ALVES, Paulo Caetano. Técnicas de compras. Rio de Janeiro: Editora FGV, 2009.

SILVA, Edna Lúcia da; MENEZES, Estera Muszkat. Metodologia da pesquisa e elaboração de dissertação. 3. ed. Florianópolis: Laboratório de Ensino A Distância da UFSC, 2001.

SLACK, N.; CHAMBERS, S.; JOHNSTON, R. Administração da produção. São Paulo: Atlas S.A., 2009.

TRIGUEIRO, Fernando Guilhobel Rosas. Administração de Materiais: um Enfoque Prático - Visão Logística. 7. ed. Recife: Focus Edições, 2007. 